\title{
Synchronous bilateral Paget's disease of the breast: A case report
}

\author{
BOJIAN XIE ${ }^{1}$, HAIHONG ZHENG ${ }^{2}$, HUANRONG LAN ${ }^{3}$, BINBIN CUI $^{1}$, KETAO JIN $^{1}$ and FEILIN CAO ${ }^{1}$ \\ Departments of ${ }^{1}$ Surgical Oncology, ${ }^{2}$ Pathology, and ${ }^{3}$ Gynecology and Obstetrics, Taizhou Hospital, \\ Wenzhou Medical College, Linhai, Zhejiang 317000, P.R. China
}

Received January 3, 2012; Accepted March 26, 2012

DOI: $10.3892 / \mathrm{ol} .2012 .676$

\begin{abstract}
Synchronous bilateral Paget's disease of the nipple is extremely rare. In the present study, we report a case of synchronous bilateral Paget's disease in a 45-year-old woman who had a medical history of gastric cancer. The patient presented with a 6-month history of eczema and itching in both nipples. Mammography and ultrasonography did not reveal any mass lesions in the bilateral breast, and computed tomography and bone scintigraphy showed no site of distant metastasis. The patient was scheduled for mastectomy and sentinel node biopsy. The histological diagnosis was Paget's disease of the breast with no evidence of underlying invasive ductal carcinoma or ductal carcinoma in situ of the breast tissue. There was no metastasis in either of the sentinel nodes. Immunohistochemical staining showed a negative expression of oestrogen and progesterone receptors. The patient has not received chemotherapy, radiotherapy or hormonal therapy. The patient has been disease-free for 7 months following surgery.
\end{abstract}

\section{Introduction}

Synchronous bilateral Paget's disease of the nipple is extremely rare. Paget's disease of the breast represents approximately $1-3 \%$ of all breast malignancies $(1,2)$ and is characterized pathologically by the presence of round intraepidermal cells of the nipple. Paget's disease can present in conjunction with an underlying invasive cancer, in conjunction with underlying ductal carcinoma in situ (DCIS), or alone without any underlying invasive breast carcinoma or DCIS (3). The majority of cases of Paget's disease have an underlying breast malignancy $(1,2)$; however, $66-86 \%$ of patients without a clinical mass on physical examination or mammogram have DCIS alone. Early reports described the occurrence of Paget's disease alone without an underlying cancer as rare, representing at most $8 \%$ of patients with Paget's disease (3). The prognosis of patients who present with Paget's disease of the breast is primarily

Correspondence to: Dr Feilin Cao, Department of Surgical Oncology, Taizhou Hospital, Wenzhou Medical College, 150 Ximen Road, Linhai, Zhejiang 317000, P.R. China

E-mail:dr.caofeilin@yahoo.com.cn

Key words: Paget's disease, breast cancer, bilateral, synchronous determined by the extent of the associated carcinoma $(1,2)$, and adjuvant treatment is administered depending on nodal and receptor status.

In this study, we present a case of synchronous bilateral Paget's disease of the breast without underlying carcinoma, which is an extremely rare phenomenon.

\section{Case report}

A 45-year-old Chinese woman admitted to our department with a 6-month history of eczema and itching in both nipples. The patient presented with no palpable mass at either breast, no obvious nipple inversion, ulceration or active nipple discharge and no sign of any palpable swelling in the lymph nodes of the axilla or supraclavicular region (Fig. 1). The patient had a medical history of gastric cancer. She had neither family history nor risk factors of breast cancer. Mammography showed no microcalcifications or mass on the breast. Chest computed tomography and breast ultrasonography revealed no abnormalities, and bone scintigraphy showed no site of distant metastasis

The clinical hypothesis of Paget's disease resulted in the patient undergoing a nipple scrape cytology, which showed isolated malignant cells of Paget's type. The tumor cells had clear cytoplasm and irregular nuclei with prominent nucleoli, which are typical features of Paget's disease (Fig. 2). These results confirmed a diagnosis of Paget's disease of the nipple, and the patient was scheduled for mastectomy and sentinel node biopsy. No complications occurred during or after surgery and she recovered well post-operatively. Histopathological examination of the specimen identified it as Paget's disease of the breast (Fig. 3) with no evidence of underlying invasive ductal carcinoma, DCIS of the breast tissue or lymph node invasion. Immunohistochemical staining showed a negative expression of oestrogen and progesterone receptors (data not shown). The patient has been disease-free for 7 months following surgery.

\section{Discussion}

Paget's disease of the nipple, also known as Paget's disease of the breast, was initially described by Sir James Paget in 1874 $(1,2)$. Paget's disease was defined as the relationship between chronic eczema of the nipple and underlying impalpable breast carcinoma. The disease is frequently mistaken for a benign dermatological condition, such as dermatitis of the nipple. This results in delayed diagnosis. Thus, a skin biopsy or scrape 


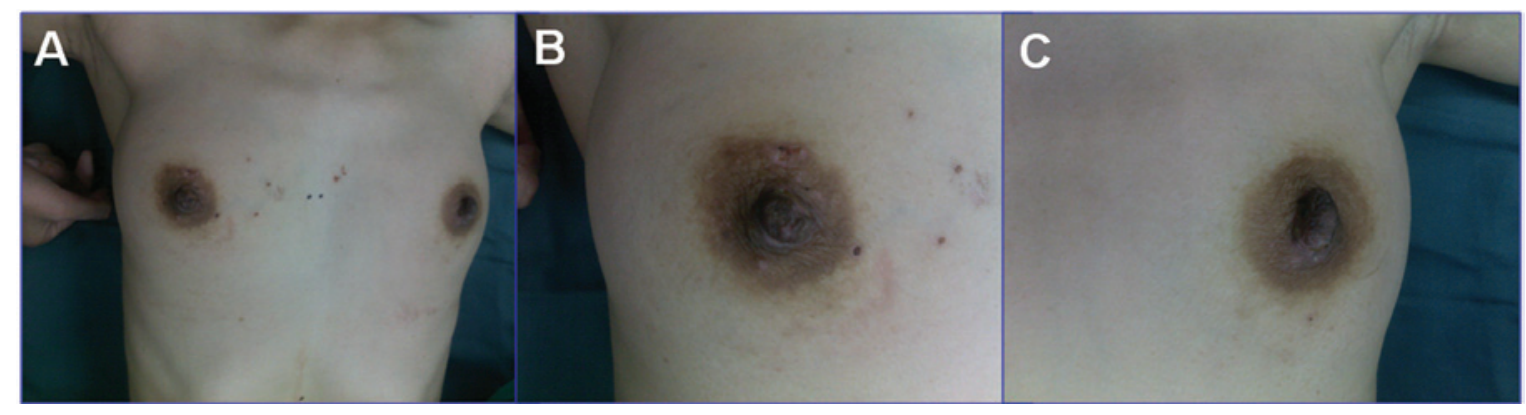

Figure 1. Initial presentation of the patient: (A) double nipple lesions; (B) the right nipple lesion; (C) the left nipple lesion.

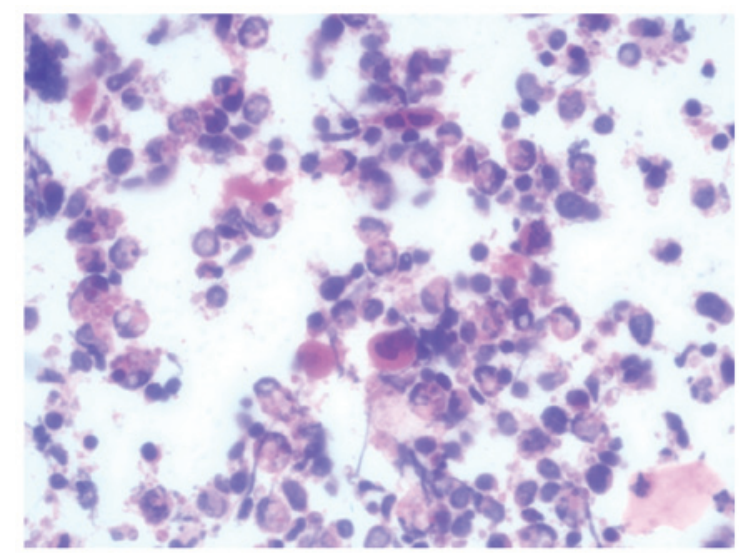

Figure 2. Cytological scraping from the skin of the nipple. (H\&E staining; magnification, $\mathrm{x} 400)$.

cytology of the eczematous area is highly recommended to exclude or confirm a diagnosis of Paget's disease in such cases.

Although Paget's disease of the breast and synchronous bilateral breast cancer are uncommon (4), synchronous bilateral Paget's disease is extremely rare $(5,6)$. Only a few cases of synchronous bilateral breast cancer with Paget's disease have been described worldwide $(5,6)$. To the best of our knowledge, there are fewer than 10 cases of bilateral Paget's disease of the breast described in the literature. We did not encounter any cases of synchronous bilateral Paget's disease of the breast without any underlying invasive breast carcinoma or DCIS.
Although the presence of the intraepidermal Paget's cell is the main pathological characteristic of this disease, the origin of the Paget's cell has yet to be conclusively determined (7). Two main hypotheses have been proposed to explain its pathogenesis (7). The epidermotropic hypothesis states that Paget's cells originate from ductal epithelium, where they migrate towards the epidermis. This hypothesis is verified by the association between Paget's disease and an underlying breast carcinoma in the majority of patients. Conversely, the intraepidermal transformation hypothesis states that malignant keratinocytes originate from the areolar epidermis (7). Currently, the epidermotropic hypothesis is more widely accepted. However, findings of our case support the intraepidermal transformation hypothesis, since there is no underlying carcinoma.

The above-mentioned theories are plausible; however, each theory of pathogenesis entails a markedly different approach to treatment (7). Mastectomy or subcutaneous mastectomy with nipple excision has conventionally been recommended based on Paget's original report and several historical studies $(1,8)$. However, advances have been made in the treatment of the Paget's disease of the breast. In their study, Pierce et al (9) examined 30 patients with Paget's disease of the breast who did not present with a palpable breast mass or mammographic density involving complete resection of the nipple-areola complex followed by definitive radiotherapy. Their results indicated that breast-conserving therapy is a viable alternative to mastectomy in the treatment of Paget's disease. A high rate of false-negative findings on mammography and a high incidence of multicentric or multifocal in situ and invasive carcinomas

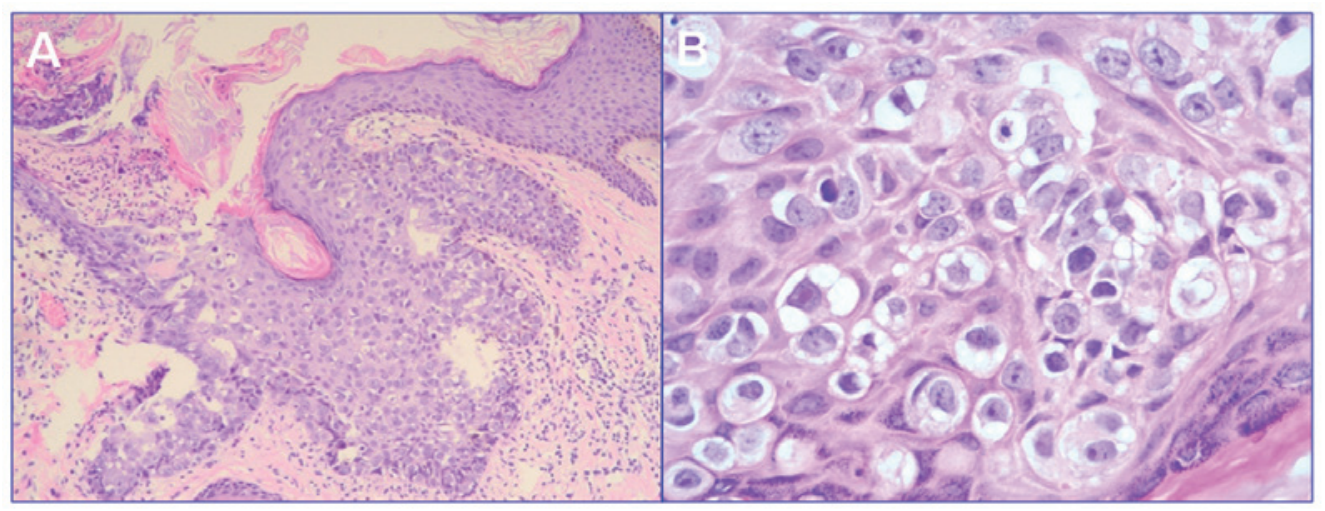

Figure 3. Microscopic examination of the specimen using H\&E staining. (A) The epidermis of the nipple infiltrated by large Paget's cells with pale abundant cytoplasm (magnification, x100). (B) Single groups of Paget's cells with vesicular nuclei and prominent nucleoli (magnification, $\mathrm{x} 400$ ). 
were identified in mastectomy specimens. In short, Paget's disease is frequently associated with underlying peripheral or multicentric breast cancer. Therefore, mastectomy with sentinel node biopsy (SNB) is probably the best treatment option for the majority of patients (10).

The prognosis of patients with synchronous bilateral breast cancer does not differ from that of patients with unilateral breast cancer. Our patient had bilateral early lesions, both of which were Paget's disease. She has been healthy without any evidence of recurrence for seven months following surgery. Thus, it is reasonable that all nipple changes be explained at the first opportunity to diagnose the disease when no palpable mass is present (11). Mammography is crucial for patients with clinical evidence of Paget's disease of the nipple in order to plan an optimal therapeutic strategy once the underlying malignancy has been detected. Improvements in mammography and, in particular, magnetic resonance imaging (MRI) techniques have resulted in a higher rate of detection of early-stage breast cancers (12). It is possible that synchronous bilateral breast cancer, with or without Paget's disease, may be identified by chance. When we encounter a patient with Paget's disease, the possibility of non-palpable early lesions underlying the breast should be considered (13).

\section{Acknowledgements}

This study was supported by Zhejiang Provincial Medical and Healthy Science and Technology Projects (Grant no. 2011KYB137), Science Research Fund of Taizhou (Grant no. A102KY09), Science Research Fund of Shaoxing (Grant no. 2011D10013), and Science Research Fund of Zhuji (Grant no. 2011CC7874).

\section{Reference}

1. Ashikari R, Park K, Huvos AG and Urban JA: Paget's disease of the breast. Cancer 26: 680-685, 1970.

2. Marshall JK, Griffith KA, Haffty BG, Solin LJ, Vicini FA, McCormick B, Wazer DE, Recht A and Pierce LJ: Conservative management of Paget disease of the breast with radiotherapy: 10- and 15-year results. Cancer 97: 2142-2149, 2003.

3. Chen CY, Sun LM and Anderson BO: Paget disease of the breast: changing patterns of incidence, clinical presentation, and treatment in the U.S. Cancer 107: 1448-1458, 2006.

4. Nakayama H, Masuda H, Ugajin W, Nakamura Y, Akiyama K, Suzuki K and Amano S: Quadruple cancer including bilateral breasts, Vater's papilla, and urinary bladder: report of a case. Surg Today 29: 276-279, 1999.

5. Anderson WR: Bilateral Paget's disease of the nipple: case report. Am J Obstet Gynecol 134: 877-878, 1979.

6. Fernandes FJ, Costa MM and Bernardo M: Rarities in breast pathology. Bilateral Paget's disease of the breast - a case report. Eur J Surg Oncol 16: 172-174, 1990.

7. Sakorafas GH, Blanchard K, Sarr MG and Farley DR: Paget's disease of the breast. Cancer Treat Rev 27: 9-18, 2001.

8. Dixon AR, Galea MH, Ellis IO, Elston CW and Blamey RW: Paget's disease of the nipple. Br J Surg 78: 722-723, 1991.

9. Pierce LJ, Haffty BG, Solin LJ, McCormick B, Vicini FA, Wazer DE, Recht A, Strawderman M and Lichter AS: The conservative management of Paget's disease of the breast with radiotherapy. Cancer 80: 1065-1072, 1997.

10. Siponen E, Hukkinen K, Heikkilä P, Joensuu H and Leidenius M: Surgical treatment in Paget's disease of the breast. Am J Surg 200: 241-246, 2010.

11. Piekarski J, Jeziorski A, Baklinska M, Szymczak W, Zadrozny M and Berner J: Patients with Paget disease of nipple and with palpable mass in breast have unfavorable prognosis. J Exp Clin Cancer Res 23: 33-37, 2004.

12. Frei KA, Bonel HM, Pelte MF, Hylton NM and Kinkel K: Paget disease of the breast: findings at magnetic resonance imaging and histopathologic correlation. Invest Radiol 40: 363-367, 2005.

13. Kijima Y, Owaki T, Yoshinaka H and Aikou T: Synchronous bilateral breast cancer with Paget's disease and invasive ductal carcinoma: report of a case. Surg Today 33: 606-608, 2003. 